\title{
Statistical characteristics of Doppler spectral width as observed by the conjugate SuperDARN radars
}

\author{
K. Hosokawa ${ }^{1}$, E. E. Woodfield ${ }^{2}$, M. Lester ${ }^{2}$, S. E. Milan ${ }^{2}$, N. Sato ${ }^{3}$, A. S. Yukimatu ${ }^{3}$, and T. Iyemori ${ }^{4}$ \\ ${ }^{1}$ Department of Geophysics, Graduate School of Science, Kyoto University, Kyoto, Japan \\ ${ }^{2}$ Department of Physics and Astronomy, University of Leicester, Leicester, UK \\ ${ }^{3}$ National Institute of Polar Research, Tokyo, Japan \\ ${ }^{4}$ Data Analysis Center for Geomagnetism and Space Magnetism, Graduate School of Science, Kyoto University, Kyoto, Japan
}

Received: 6 September 2001 - Revised: 5 March 2002 - Accepted: 11 March 2002

\begin{abstract}
We performed a statistical analysis of the occurrence distribution of Doppler spectral width around the dayside high-latitude ionosphere using data from the conjugate radar pair composed of the CUTLASS Iceland-East radar in the Northern Hemisphere and the SENSU Syowa-East radar in the Southern Hemisphere. Three types of spectral width distribution were identified: (1) an exponential-like distribution in the lower magnetic latitudes (below $72^{\circ}$ ), (2) a Gaussian-like distribution around a few degrees magnetic latitude, centered on $78^{\circ}$, and (3) another type of distribution in the higher magnetic latitudes (above $80^{\circ}$ ). The first two are considered to represent the geophysical regimes such as the LLBL and the cusp, respectively, because they are similar to the spectral width distributions within the LLBL and the cusp, as classified by Baker et al. (1995). The distribution found above $80^{\circ}$ magnetic latitude has been clarified for the first time in this study. This distribution has similarities to the exponential-like distribution in the lower latitude part, although clear differences also exist in their characteristics. These three spectral width distributions are commonly identified in conjugate hemispheres. The latitudinal transition from one distribution to another exhibits basically the same trend between two hemispheres. There is, however, an interhemispheric difference in the form of the distribution around the cusp latitudes, such that spectral width values obtained from Syowa-East are larger than those from IcelandEast. On the basis of the spectral width characteristics, the average locations of the cusp and the open/closed field line boundary are estimated statistically.
\end{abstract}

Key words. Ionosphere (ionosphere-magnetosphere interactions; plasma convection) - Magnetospheric physics (magnetopause, cusp, and boundary layers)

Correspondence to: $\mathrm{K}$. Hosokawa

(hosokawa@kugi.kyoto-u.ac.jp)

\section{Introduction}

Determining the open/closed field line boundary (OCFLB) around the dayside ionosphere enables us to estimate several geophysical parameters such as (1) the rate of reconnection at the magnetopause, (2) the size of polar cap, and (3) the creation and destruction of open magnetic flux associated with the dayside and nightside reconnection. Direct observations of the cusp particle precipitation by the low-altitude spacecrafts such as DMSP (e.g. Newell and Meng, 1988, 1991) are most widely utilized as a proxy for the OCFLB. The optical auroral signature triggered by cusp particle precipitation has also been a good guide for the identification of the OCFLB (Sandholt et al., 1998).

The dayside auroral zone provides a good target for HF radars (Milan et al., 1998). A relationship between the magnetospheric cusp particle precipitation into the ionosphere and the HF radar backscatter from the ionospheric $\mathrm{F}$ region has been reported by a number of authors (Baker et al., 1990, 1995; Rodger et al., 1995; Yeoman et al., 1997). They demonstrated that the equatorward edge of radar backscatter showing broad Doppler spectral widths is coincident with the equatorward edge of the cusp particle precipitation. Furthermore, the equatorward edge of these regions of HF radar backscatter appear to correspond closely to the equatorward edge of the $630.00 \mathrm{~nm}$ (red line) aurora during the period of negative IMF $B_{z}$ (Rodger et al., 1995; Milan et al., 1999; Moen et al., 2001). Baker et al. (1995) analyzed the HF radar data for eight cusp events and eight low-latitude boundary layer (LLBL) events which were identified by the DMSP satellite. They reported that the distribution of observed spectral widths in the cusp is significantly different from that observed in the LLBL. The distribution of spectral widths within the cusp is a broad Gaussian shaped distribution, whose average is around $220 \mathrm{~m} \mathrm{~s}^{-1}$ (termed cusp-type distribution in this paper). In contrast, the distribution of spectral widths in the LLBL is more similar to an exponential distribution, with the peak occurring at about $50 \mathrm{~m} \mathrm{~s}^{-1}$ (termed 


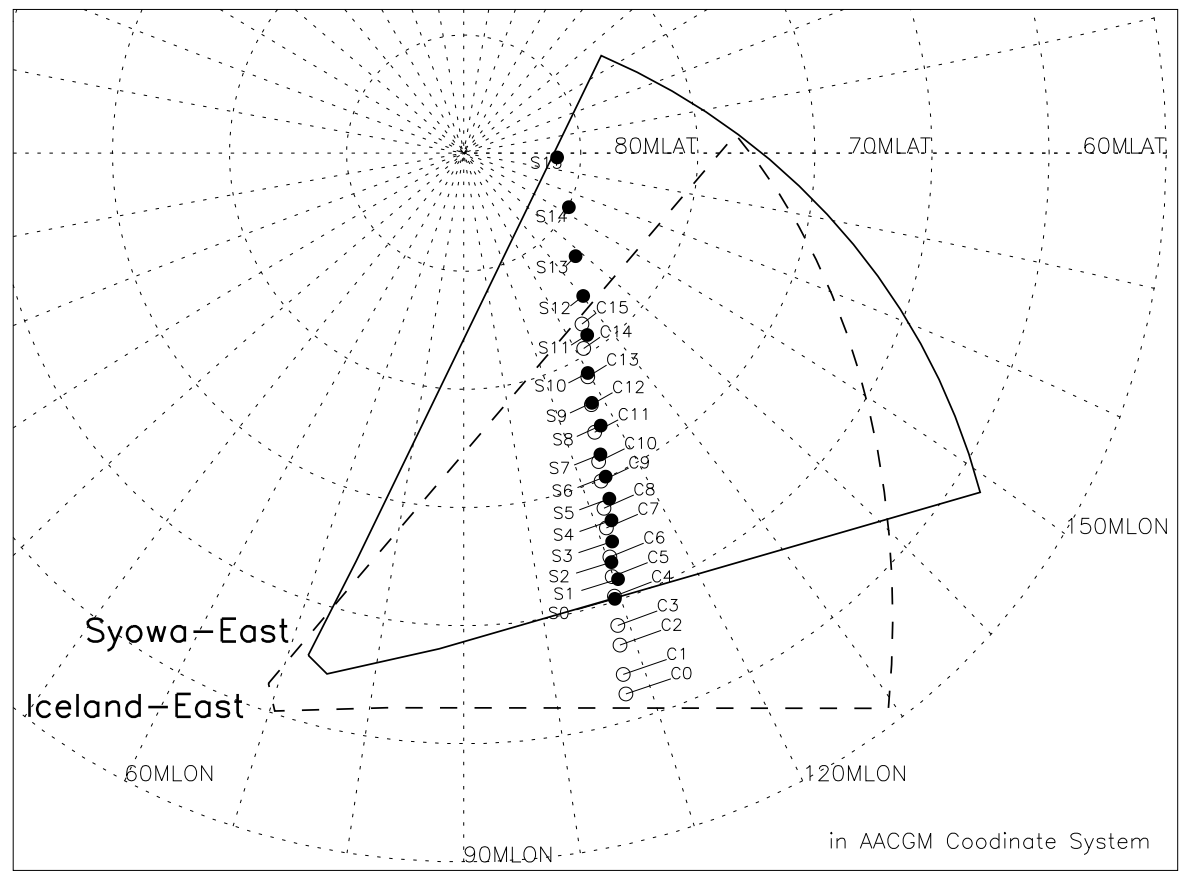

Fig. 1. The location of the summary point arrays within the field-of-view of CUTLASS Iceland-East and SENSU Syowa-East radars which are mapped into the AACGM coordinate system in the Northern Hemisphere. The solid fan-shaped area indicates the field-of-view of SyowaEast and dashed indicates that of Iceland-East. The summary points and the field-of-view of Syowa-East radar are mapped into the Northern Hemisphere using the IGRF95 model. Open circles indicate the summary points of Iceland-East from $\mathrm{C} 0$ to $\mathrm{C} 15$ and filled circles indicate those of Syowa-East from S0 to S15.

LLBL-type distribution in this paper). The boundary between these two types of spectral width distribution has been considered to be the OCFLB in the HF radar observation, though it is possible that there is a displacement of radar signature of the OCFLB from the real OCFLB (for a discussion, see Milan et al., 2001b).

A number of previous papers have examined the HF radar spectral width signatures around the dayside ionosphere through case studies, and also statistical characteristics of spectral width have been examined by Villain et al. (2002) using the data from all the Northern Hemisphere SuperDARN radars. However, there have been only a few simultaneous observations of the cusp and the OCFLB using the data from magnetic conjugate radars (Pinnock et al., 1999; Milan and Lester, 2001). These conjugate studies employed the data of the Polar Anglo-American Conjugate Radar Experiment (PACE) radars located at Goose Bay, Canada, and Halley, Antarctica which are part of the SuperDARN chain (Greenwald et al., 1995). In this paper, we employed another magnetic conjugate radar pair in the SuperDARN chain which is composed of the Iceland-East radar of the Coordinated UK Twin-Located Auroral Sounding System (CUTLASS) and the Syowa-East radar of Syowa-South and East HF Radars of NIPR for SuperDARN (SENSU). For the first time, statistical characteristics of spectral width distributions in magnetically conjugate ionospheres have been compared. Consequently, significant interhemispheric differences in the characteristics of spectral width distribution are found and the statistical locations of the cusp and the OCFLB were determined in both hemispheres.

\section{Database and analysis}

\subsection{Statistics database}

Common Time Operation data of CUTLASS Iceland-East in the Northern Hemisphere and SENSU Syowa-East in the Southern Hemisphere have been employed for this study. In the current version of Common Time Operation Normal Scan Mode, the radar scans through 16 beams, each beam being binned into 75 range gates (70 range gates in the case of SENSU radars). Hence, one complete scan, obtained every 2 min, covers a fan-shaped area with 1200 cells (1120 cells for SENSU radars). To allow for statistical analysis of long periods of observations, Milan et al. (1997) designated 16 cells from the total of 1200 as "summary points" and created a data base for the CUTLASS radars. In a similar way, we determined summary points and constructed a data base for the SENSU Syowa-East radar. In the statistical analysis, we used the 36 months of data from January 1998 to December 2000 of CUTLASS Iceland-East and SENSU Syowa-East radars.

Figure 1 presents the location of the summary point arrays in the field-of-view of CUTLASS Iceland-East and SENSU Syowa-East, which are mapped into the AACGM coordinate system (based on Baker and Wing, 1989) in the Northern 

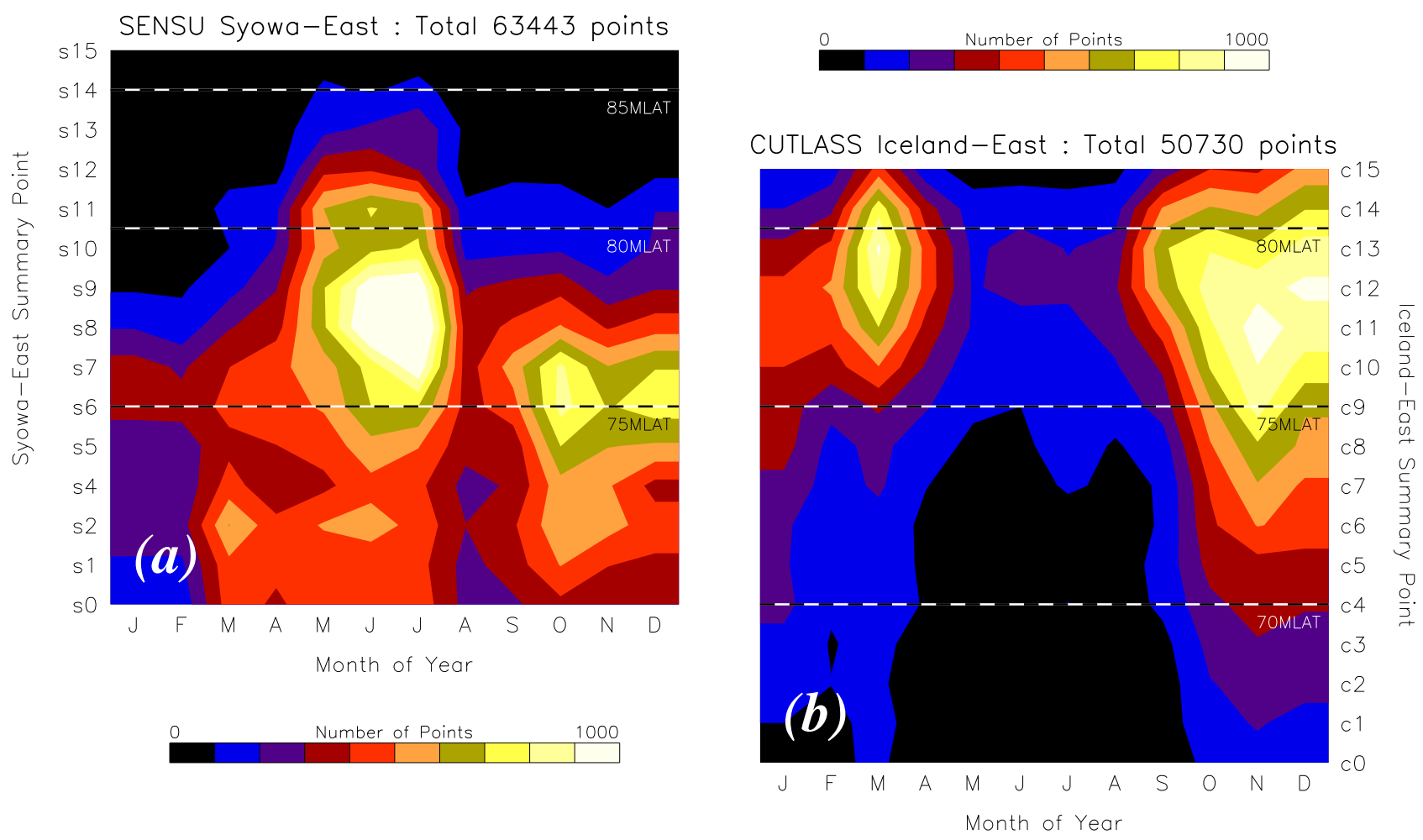

Fig. 2. Color-coded number of data points as a function of month obtained by (a) SENSU Syowa-East radar and (b) CUTLASS Iceland-East radar during the interval of our statistical analysis. The vertical axis indicates the summary points from S0 to S15 for Syowa-East and C0 to $\mathrm{C} 15$ for Iceland-East, and the horizontal axis is the month of the year.

Hemisphere. The summary points and the field-of-view of Syowa-East are mapped into the Northern Hemisphere using the IGRF95 model. Open circles indicate the summary points of Iceland-East (from $\mathrm{C} 0$ to $\mathrm{C} 15$ ) and filled circles indicate those of Syowa-East (from S0 to S15). We emphasize that the Syowa-East summary points from S0 to S11 are determined to be located to the magnetic conjugate point of the Iceland-East summary points from $\mathrm{C} 4$ to $\mathrm{C} 15$. Intersection of the two summary point arrays ranges from $70^{\circ}$ to $81^{\circ}$ in magnetic latitude, which lies from the average position of the LLBL to the polar cap, through the OCFLB and the cusp in the radar observation around the dayside ionosphere. The difference in magnetic longitude of the overlapping points is approximately $10^{\circ}$.

To clarify the characteristics of spectral width distribution in the dayside high-latitude ionospheres, we used the radar data taken during $6 \mathrm{~h}$ of magnetic local time centered at local magnetic noon (09:00-15:00 MLT). Echoes that are considered to be ground scatter were excluded on the basis of FITACF analysis (Villain et al., 1987; Baker et al., 1995). Furthermore, echoes which do not have a sufficiently strong signal ( $<3 \mathrm{~dB}$ signal-to-noise ratio) were eliminated in order to remove much of the ghost scatter due to radio interference. After the elimination of non-ionospheric backscatter, we classified the spectral widths into twenty five bins covering $0-500 \mathrm{~m} \mathrm{~s}^{-1}$, each with a range of $20 \mathrm{~m} \mathrm{~s}^{-1}$, and investigated the occurrence distribution of the spectral widths.

\subsection{Geophysical bias}

For the time interval from January 1998 to December 2000, we obtained 63443 observations of spectral width at the summary points of the Syowa-East radar in the Southern Hemisphere and 50730 the Iceland-East radar in the Northern Hemisphere. The Syowa-East radar observes about 25\% more backscatter than the Iceland-East radar. The occurrence of ionospheric backscatter is strongly affected by the HF propagation condition that is mainly associated with ionospheric electron density structure (Milan et al., 1997). Thus, the difference in the data points between the two radars might be due to the difference in the propagation condition between the two hemispheres. Although there is a slight difference in the data points between the two radars, the number of data points is large enough to illustrate the average characteristics of the spectral width distribution in both hemispheres. When we process a large data set in a statistical manner, it is very important to characterize the data base. Here, geophysical biases in our data base due to season and magnetic local time are examined and their effects on our statistical analysis are estimated.

All of the SuperDARN HF radars have an enhanced probability of observing ionospheric scatters around the dayside local time sector during the winter months (Ruohoniemi and Greenwald, 1997; Milan et al., 1997; Hosokawa et al., 2001). This winter effect might be caused by the differences in the 

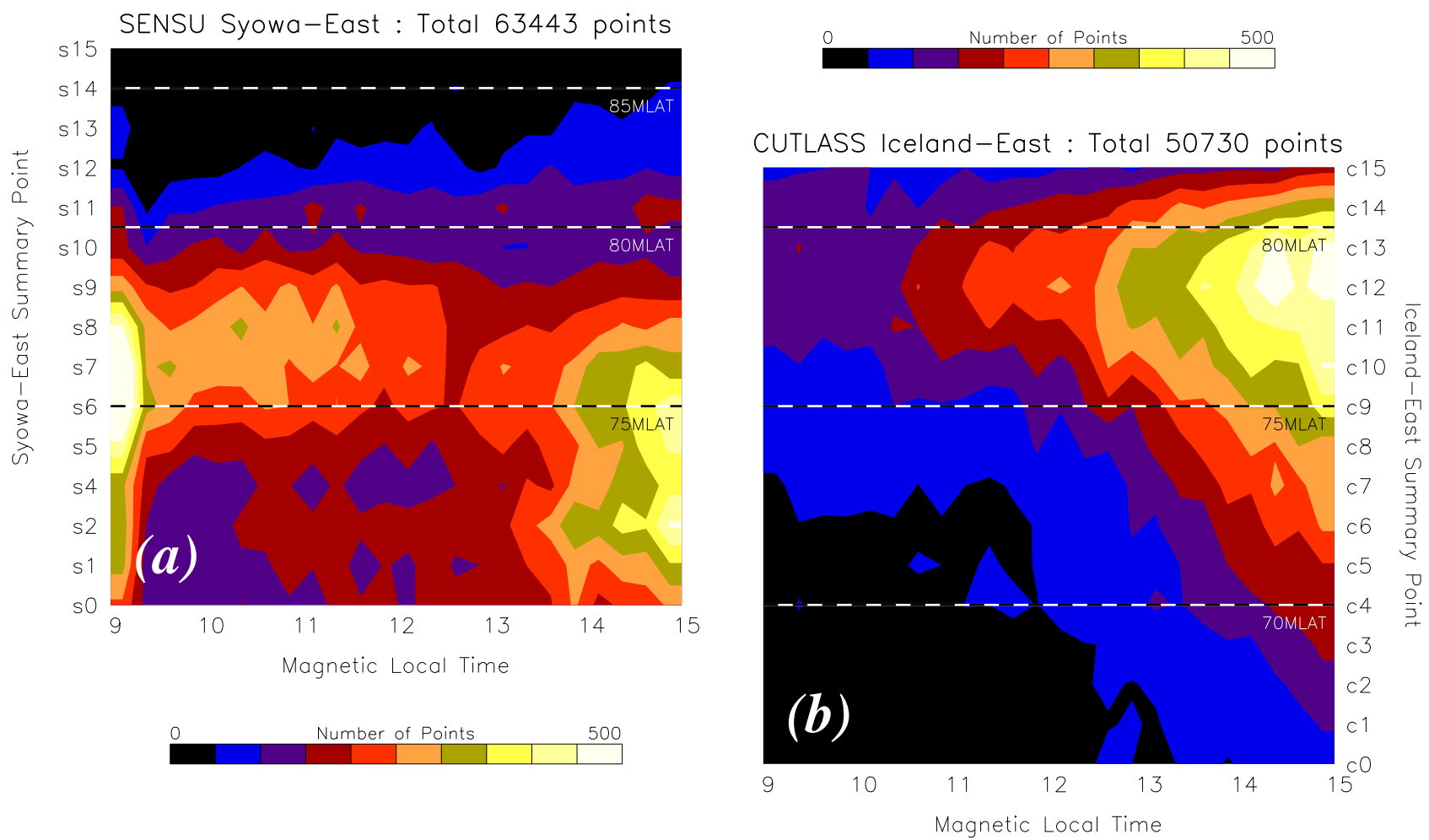

Fig. 3. Color-coded number of data points as a function of magnetic local time obtained by (a) SENSU Syowa-East radar and (b) CUTLASS Iceland-East radar during the interval of our statistical analysis. The vertical axis indicates the summary points from S0 to S15 for Syowa-East and $\mathrm{C} 0$ to $\mathrm{C} 15$ for Iceland-East, and the horizontal axis is the magnetic local time from 09:00 to 15:00 MLT.

propagation condition in sunlit and dark hemispheres or the difference in the growth rate of the gradient-drift instability process which creates irregularities as a target of the HF radar backscatter (Milan et al., 1997; Villain et al., 2002). Figure 2 displays the number of data points color-coded as a function of month obtained by (a) the SENSU Syowa-East radar and (b) the CUTLASS Iceland-East radar, during the interval of our statistical study. The vertical axis shows the summary points from S0 to S15 for Syowa-East (data of $\mathrm{S} 3$ are not displayed in this figure, because S3 has no corresponding summary point in Iceland-East) and $\mathrm{C} 0$ to $\mathrm{C} 15$ for Iceland-East, and the horizontal axis is the month of the year. Since the summary points of Syowa-East are located at relatively higher latitudes compared with those of IcelandEast, Fig. 2a is shifted by 4 summary points upward along the vertical axis. Our statistical database also exhibits an enhancement of backscatter occurrence during winter months in both hemispheres. Hence, the statistical results obtained in this study are considered to be dominated by the data observed during the winter months. However, the coverage of the data employed in this study extends from January 1998 to December 2000, and both radars cover three winters in common. This suggests that this winter effect cannot be a major bias on our statistical analysis of the spectral width. On the other hand, summer data are mainly obtained by the Syowa-East at magnetic latitudes below S8 (approximately $77^{\circ}$ ). It could affect the interhemispheric comparison at the low-latitude part of the summary point array, but not within the average latitudes of the cusp.

Figure 3 gives the number of data points color-coded as a function of magnetic local time, between 09:00 and 15:00 MLT, and summary points obtained by (a) SENSU Syowa-East radar and (b) CUTLASS Iceland-East radar. A large amount of data points is obtained in the postnoon sector for the case of the Iceland-East radar. This tendency is consistent with the backscatter occurrence statistics of the Iceland-East radar provided by Milan et al. (1997). In contrast, the distribution of the data points in the Syowa-East radar is more uniform with magnetic local time than that in Iceland-East. This result suggests that there is a considerable difference in data point distribution between the two radars and we must keep in mind the possibility that this could introduce a bias on the statistical analysis of spectral width. The effect of this bias on the spectral width distribution is also discussed in the next section.

\section{Statistical results}

\subsection{Latitudinal variation of the spectral width distribution}

Figure 4 gives the occurrence distribution of spectral widths observed by (a) the SENSU Syowa-East radar and (b) the CUTLASS Iceland-East radar, within the magnetic local times from 09:00 to 15:00 MLT. The vertical axis shows the 

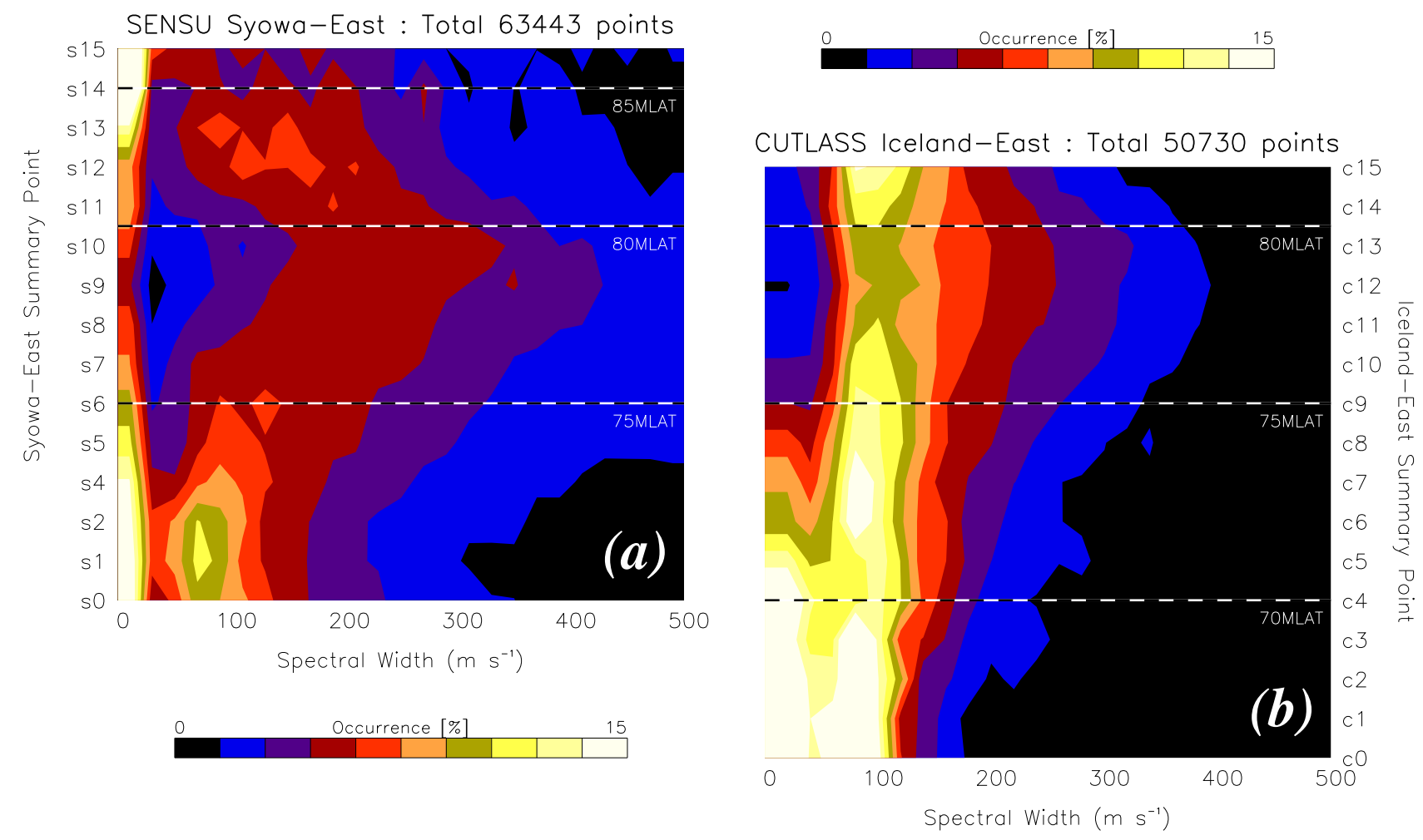

Fig. 4. The occurrence distribution of spectral widths observed by (a) SENSU Syowa-East radar and (b) CUTLASS Iceland-East radar. The vertical axis indicates the summary points from S0 to S15 for Syowa-East and C0 to C15 for Iceland-East, and the horizontal axis is the spectral width.

summary points and the horizontal axis is the spectral width. The percentage occurrence distribution for each summary point is normalized by the total number of points at that summary point. Coverage of the summary points extends from $70^{\circ}$ to $86^{\circ}$ for Syowa-East and from $66^{\circ}$ to $81^{\circ}$ for IcelandEast. Hence, the region where we can compare directly the spectral width distributions of both radars ranges from S0 to S11 in Syowa-East and C4 to C15 in Iceland-East, which corresponds to the magnetic latitude range of $70^{\circ}-81^{\circ}$. One thing we must note is that the peaks of the occurrence at first spectral width bins $\left(0-20 \mathrm{~m} \mathrm{~s}^{-1}\right)$ in the Syowa-East data are mainly due to a contamination of ground scatter and are out of scope for this paper. This means that backscatter echoes exist from the ground, whose Doppler velocity is larger than the criterion for identifying ground scatter in the FITACF procedure.

Figure $4 \mathrm{~b}$ shows that the occurrences are fairly localized around the spectral width values that are less than $150 \mathrm{~m} \mathrm{~s}^{-1}$ at the magnetic latitudes below $70^{\circ}$, which is equivalent to the summary points between $\mathrm{C} 0$ and $\mathrm{C} 4$ in Iceland-East. Also within the magnetic latitudes between $70^{\circ}$ and $72^{\circ}$, which correspond to the summary points between S0 and $\mathrm{S} 2$ of Syowa-East and between C4 and C6 of Iceland-East, narrow spectral width values that are less than $200 \mathrm{~m} \mathrm{~s}^{-1}$ are dominant in both radars. These features correspond to the LLBL-type spectral width distribution, as identified by Baker et al. (1995). Above $72^{\circ}$ magnetic latitude, the form of the distribution gradually changes as the magnetic latitude increases and another type of distribution appears around magnetic latitudes centered at S9 in Syowa-East and $\mathrm{C} 12$ in Iceland-East, that is approximately $78^{\circ}$. Around this magnetic latitude, the occurrence rate of narrow spectral width becomes lower and spectral widths are distributed in a broader range. This type of distribution is considered to correspond to the cusp-type distribution as described in Baker et al. (1995). Transition from the LLBL-type spectral width distribution to the cusp-type is seen around the magnetic latitudes from $74^{\circ}$ to $76^{\circ}$ in both hemispheres. It is also worth noting that the narrow spectral width values tend to be dominant again above $80^{\circ}$ in magnetic latitude. This tendency is most clearly seen in Syowa-East, although there is some evidence for this in the data from Iceland-East. These observations suggest that another type of spectral width distribution exists above $80^{\circ}$ in magnetic latitude. This type of distribution has similarities to the LLBL-type spectral width distribution, but clear differences exist in their characteristics. The details of these three types of spectral width distributions will be discussed in the later part of this section.

\subsection{Longitudinal variation of the spectral width distribution}

As noted in the previous section, bias due to the data point distribution in magnetic local time direction could affect the statistical results shown in Fig. 4, because we merged the 

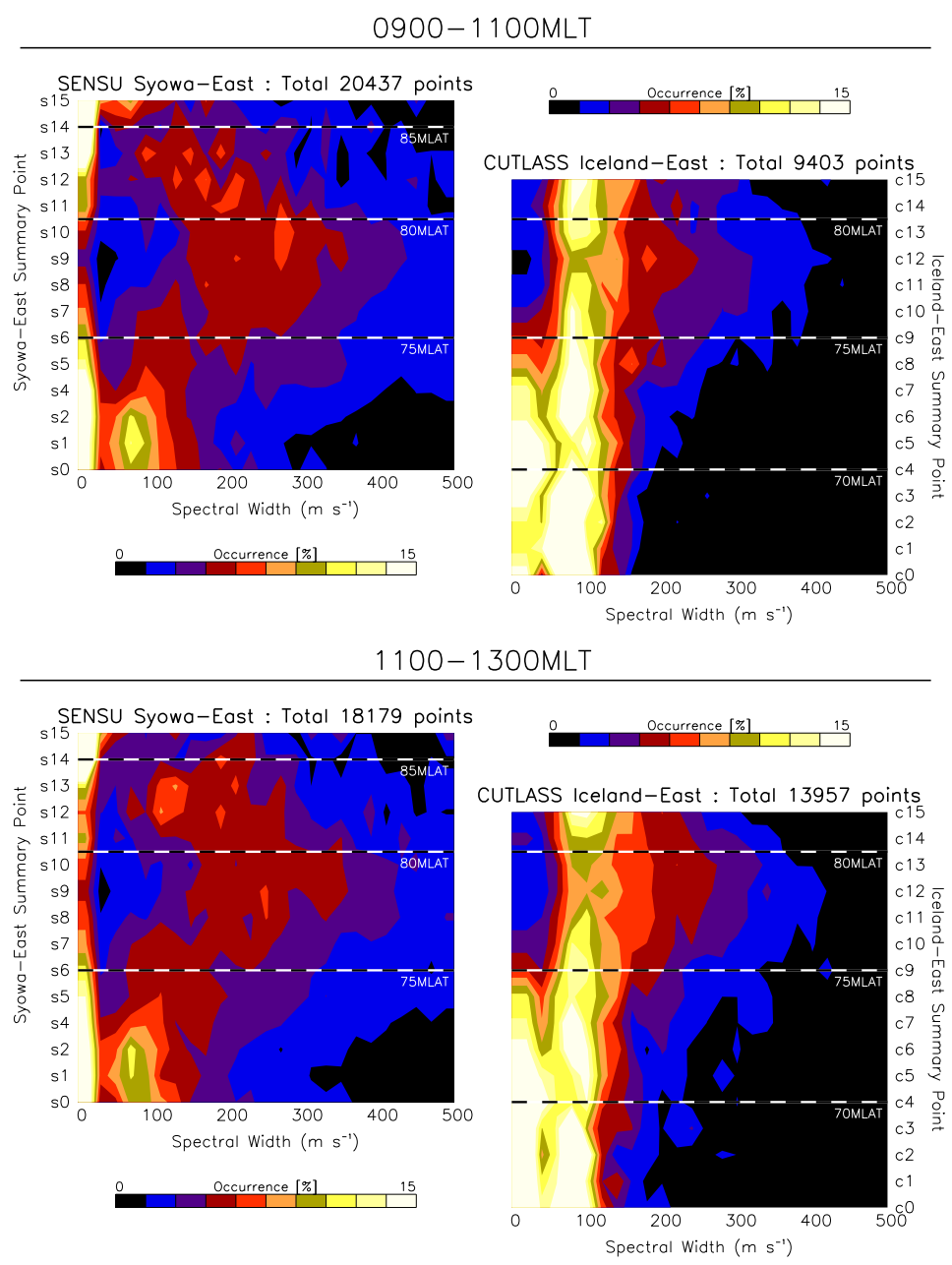

1300-1500MLT
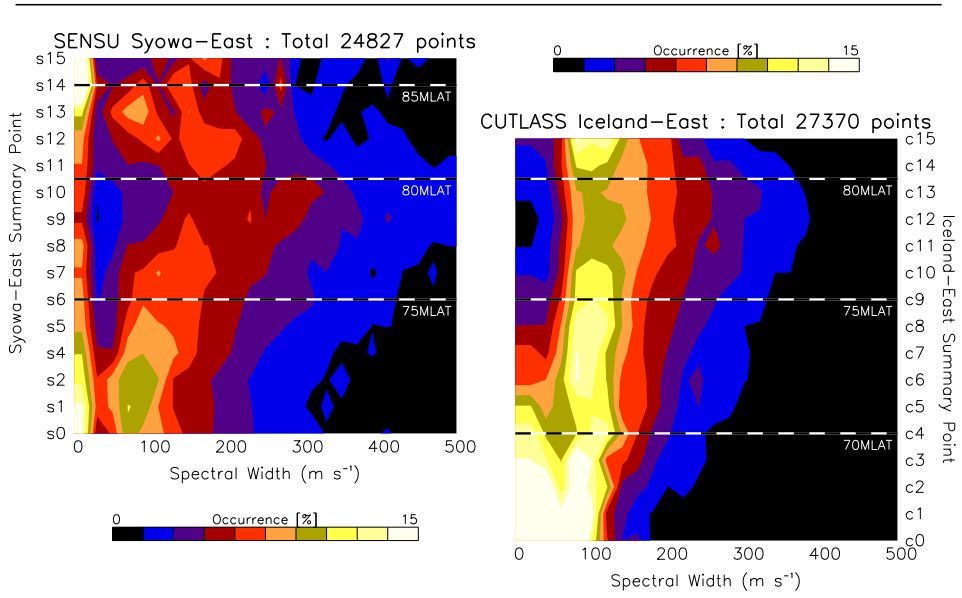

Fig. 5. Variation of spectral width distribution with magnetic local time. The distributions are shown in same form of contour as Fig. 4 for three magnetic local time sectors: prenoon sector (09:00-11:00 MLT; top panel), noon sector (11:00-13:00 MLT; middle panel), and postnoon sector (13:00-15:00 MLT; bottom panel), respectively.

data measured in the interval from 09:00 to 15:00 MLT in Fig. 4. Figure 5 shows the variation of spectral width distribution with magnetic local time for both radars. The distributions are shown in a contour similar form for three mag- netic local time sectors: prenoon sector (09:00-11:00 MLT, top panels), noon sector (11:00-13:00 MLT, middle panel) and postnoon sector (13:00-15:00 MLT, bottom panels), respectively. Although the number of data points is different 

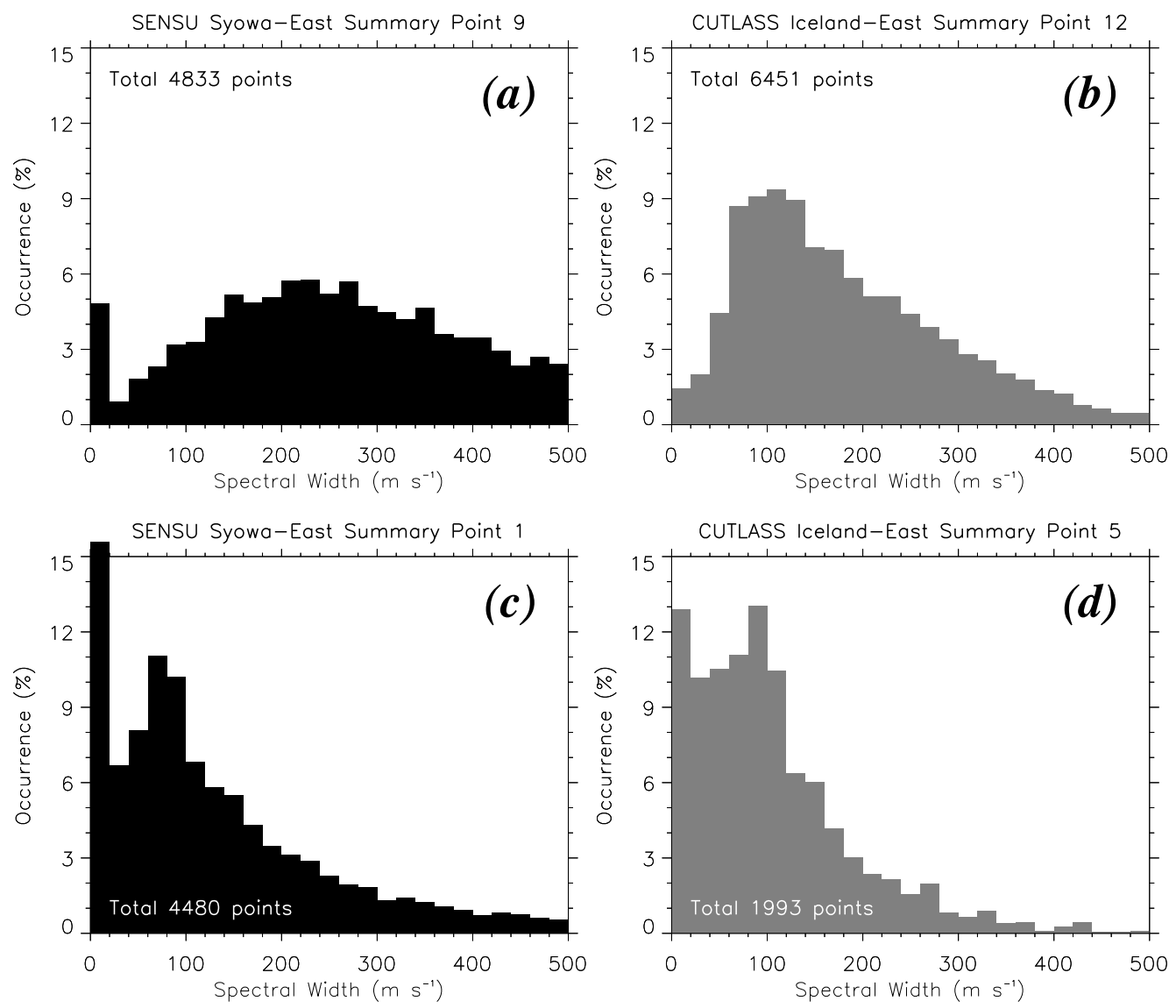

Fig. 6. The histogram of the spectral width distribution at (a) S9 in Syowa-East, (b) C12 in Iceland-East, (c) S1 in Syowa-East and (d) C5 in Iceland-East.

between the magnetic local time sectors, the general trend of the spectral width distribution is common among all magnetic local time sectors. This fact suggests that bias due to the data point distribution in magnetic local time direction does not affect the spectral width distribution drastically, which allows us to investigate the characteristics of spectral width around the dayside ionosphere, using the data obtained within the magnetic local time from 09:00 to 15:00 MLT.

\subsection{Form of the spectral width distribution}

The most significant finding in Fig. 4 is that the spectral width distributions obtained in conjugate hemispheres exhibit the same general trend with latitude. However, the distribution of spectral widths measured by Syowa-East within the average position of the cusp (around a few degrees magnetic latitude centered on $78^{\circ}$ ) differs from that at IcelandEast. The bottom two panels of Fig. 6 show the histograms of the spectral width distribution at (c) S1 in Syowa-East and (d) C5 in Iceland-East. The magnetic latitudes of these summary points are approximately $71^{\circ}$, a latitude at which the LLBL-type distribution dominates. The distribution of spectral widths takes the approximate form of an exponential distribution in both hemispheres, with most values lying within the range of 0 to $200 \mathrm{~m} \mathrm{~s}^{-1}$. One difference at these mag- netic latitudes is that the Syowa-East data have a large peak in the first spectral width bin, $0-20 \mathrm{~m} \mathrm{~s}^{-1}$. This peak is due to the contamination of the backscatter echoes from the ground and has no relation to the geophysical structures in the ionosphere. Hence, no considerable difference exists in the characteristics of the spectral width distribution between the two radars at these magnetic latitudes.

The upper two panels of Fig. 6 show the distribution of spectral width at (a) S9 in Syowa-East and (b) C12 in Iceland-East. The magnetic latitude of these summary points is about $78^{\circ}$. In the case of Syowa-East, the distribution of the spectral widths is a broad Gaussian shape, with the peak at about $220 \mathrm{~m} \mathrm{~s}^{-1}$, which is in good agreement with the cusp-type spectral width distribution found by Baker et al. (1995). However, the distribution is slightly wider in comparison with the one found by Baker et al. (1995), i.e. the percentage of very high spectral width $\left(>350 \mathrm{~m} \mathrm{~s}^{-1}\right)$ is higher. This is due to the fact that the spectral width values used in this study are computed with a different version of the FITACF program than the one Baker et al. (1995) used in their study. Indeed, the spectral widths observed by Iceland-East are distributed in a broad range from 50 to $400 \mathrm{~m} \mathrm{~s}^{-1}$, however, the peak is found at $100 \mathrm{~m} \mathrm{~s}^{-1}$. The spectral width values obtained from Iceland-East tend to be smaller than those 


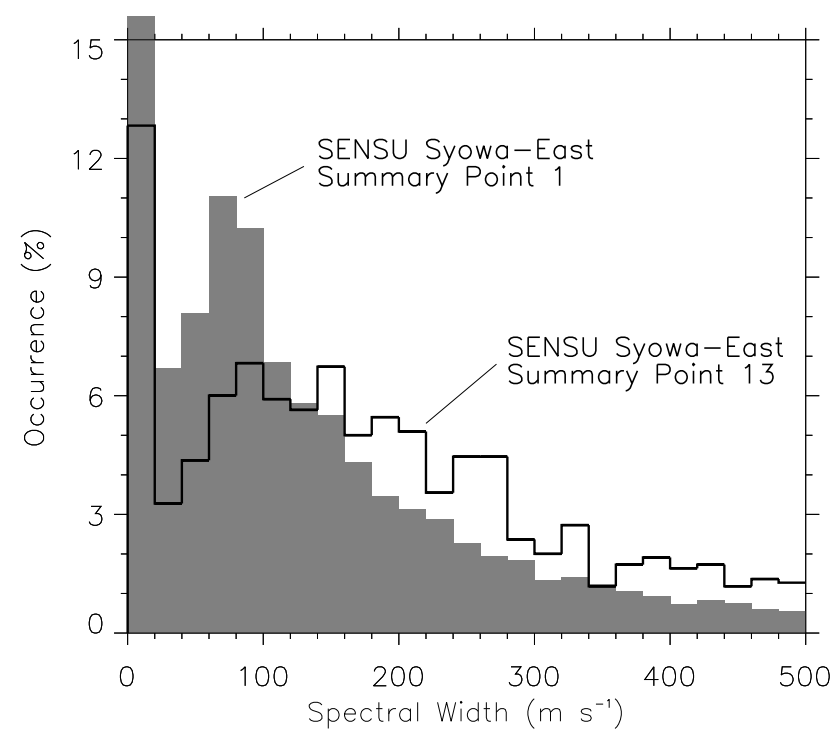

Fig. 7. The histogram of the spectral width distribution at S1 (shaded) and S13 (black line) in Syowa-East.

obtained from Syowa-East and by Baker et al. (1995). The reason why the distributions of Iceland-East are quite different from that of Syowa-East within the cusp is discussed in the next section.

As displayed in Fig. 4, another type of spectral width distribution exists above $80^{\circ}$ in magnetic latitude. This tendency is clearly seen in the Syowa-East, although there is some evidence for this in the data from Iceland-East. Figure 7 shows the histograms of the spectral width distribution at S1 (shaded) and S13 (black line) in Syowa-East. This distribution has similarities to the LLBL-type spectral width distribution, but there are the following clear differences: (1) the occurrence of higher spectral width values (above $200 \mathrm{~m} \mathrm{~s}^{-1}$ ) is higher, (2) the maximum of the distribution is found approx. above $100 \mathrm{~m} \mathrm{~s}^{-1}$, slightly greater than that of the LLBL-type distribution, and (3) the occurrence of low spectral width values (less than $100 \mathrm{~m} \mathrm{~s}^{-1}$ ) is smaller. This feature has not been identified in previous studies and an interpretation of this type of distribution will be discussed in the next section.

\section{Discussion}

\subsection{Generation mechanisms of broad spectral width}

To investigate the spectral width characteristics in detail, the median value of the distribution is computed for both radars and presented in Fig. 8. The results from SyowaEast are displayed with filled circles and those from IcelandEast are displayed with open circles, respectively. The latitudinal transition of the median value exhibits basically the same trend between conjugate hemispheres, namely the median of the distribution steadily increases from S0 to S10 for Syowa-East and from C0 to C12 for Iceland-East, and decreases from S10 to S14 for Syowa-East and C12 to C15 for
Iceland-East. Recently, André et al. (2000a) have proposed that high frequency $(\mathrm{Pc} 1)$ wave activity associated with the cusp contains highly variable electric fields which broaden the HF radar spectra. Most of these waves are attributed to electromagnetic ion cyclotron waves generated at the dayside magnetopause in the equatorial plane. André et al. (2000a) also pointed out that small-scale vortices of ionospheric convection, which are generated by the field-aligned current with structured soft electron precipitation from the dayside magnetosheath (Schiffler et al., 1997; Huber and Sofko, 2000), can broaden the spectra around the dayside ionosphere. Since both of these activities, wave and particle precipitation, are considered to propagate into the conjugate ionospheres along the magnetic field line, the ideas proposed by André et al. (2000a) can explain consistently the interhemispheric similarity in the latitudinal trend of spectral width distribution.

Present statistical analysis has also shown that there exists another type of spectral width distribution in the higher magnetic latitudes (above $80^{\circ}$ ). This distribution has similarities to the LLBL-type spectral width distribution found in the lower latitudes (below $72^{\circ}$ ), however, the occurrence of large spectral width values clearly tends to be higher. There are two possible interpretations of this distribution. One is that this distribution represents characteristics of particle precipitation peculiar to the domain poleward of the cusp, i.e. the mantle region. The mantle region consists of very low energy ions, with a low density (Newell et al., 1991). This specific nature of particle precipitation might produce the spectral width feature that different from the LLBL-type and cusp-type distributions.

The other possible interpretation is that the distribution at the highest magnetic latitude part is a result of the ionospheric signature of the cusp precipitation during northward IMF. During the period of northward IMF, the cusp is generally located at higher magnetic latitude, and characteristics of the cusp precipitation are also expected to be different from that for the southward IMF case. Since our statistical analysis merged northward and southward IMF conditions, this signature might affect the spectral width distribution at the higher latitude regime.

\subsection{Interhemispheric differences in spectral width values}

As shown in Fig. 6 and Fig. 8, there exists a interhemispheric difference in the spectral width characteristics around the average latitudes of the cusp, although the latitudinal trend of the spectral width distribution exhibits basically the same behavior. The form of the distribution is slightly different, and the median of the distribution obtained from Syowa-East is larger than that from Iceland-East, in particular the difference reaches $100 \mathrm{~m} \mathrm{~s}^{-1}$ around $78^{\circ}$. This kind of interhemispheric asymmetry in the spectral width characteristics was also reported in a case study basis by Milan and Lester (2001). They employed the other conjugate radar pair composed of SuperDARN Goose Bay and Halley radars and demonstrated that 
spectral width values obtained in the Southern Hemisphere are larger than those in the Northern Hemisphere.

First, we discuss the possibility of instrumental effects, such as the difference in beam width or noise level, on this interhemispheric asymmetry. If the interhemispheric difference in our statistics is due to an instrumental effect, the difference has to be found in common at all magnetic latitudes. However, the difference in spectral width values is smaller around the magnetic latitude below $72^{\circ}$, with differences in median values being approximately less than $30 \mathrm{~m} \mathrm{~s}^{-1}$. Also, the form of the distributions within the lower magnetic latitudes of the summary point arrays is quite similar between two hemispheres. This fact suggests that an instrumental effect does not make a significant contribution to the interhemispheric asymmetry in spectral width distributions.

Next, we discuss the effect of contamination by non Fregion backscatters. SuperDARN radars often observe the spectra that includes several sources, such as F-region scatter, E-region scatter and ground scatter. Milan et al. (1997) reported that Type I E-region backscatter echoes, as well as Fregion backscatter, can be observed at far radar ranges during winter months. Barthes et al. (1998) demonstrated that if the spectra is composed of both ionospheric and ground scatter, the spectral width value derived from the FITACF analysis contains error. Chisham and Pinnock (2002) also pointed out that contamination by non F-region backscatter contributes to the velocity determination of SuperDARN observations. In our statistical analysis, however, the interhemispheric difference of the median value is up to $100 \mathrm{~m} \mathrm{~s}^{-1}$ (see Fig. 8), which is considered to be too large to be explained only by the contamination of non F-region backscatters. Also, as is not shown in this paper, contaminations by ground and Eregion backscatters are commonly found in the observations of Iceland-East and Syowa-East, which also confirms that the effect of non F-region backscatter makes a minor contribution to the interhemispheric difference in the spectral width distribution.

The other possibility is that the spectral width distribution around $78^{\circ}$ magnetic latitude in the Northern Hemisphere is a mixture of the cusp-type and LLBL-type distributions, while that in the Southern Hemisphere is dominated only by the cusp-type spectral width distribution. The summary points of Iceland-East and Syowa-East are magnetically conjugate, however, their geographic latitudes and longitudes are slightly different. This displacement could cause the difference in the radio-wave propagation path or scattering condition. Hence, the Iceland-East radar could observe the LLBLtype spectral width feature even in the average latitude of the cusp.

In addition to the contribution by the high-frequency wave activity and small-scale convection vortex created by soft particle precipitation, the gradient in the velocity distribution, which results from geometry of the radar with respect to the large-scale convection pattern, also broadens the HF radar spectra (Barthes et al., 1998; André et al., 2000a). Milan et al. (2001a) demonstrated that the dayside convection pattern could exhibit considerable asymmetries between

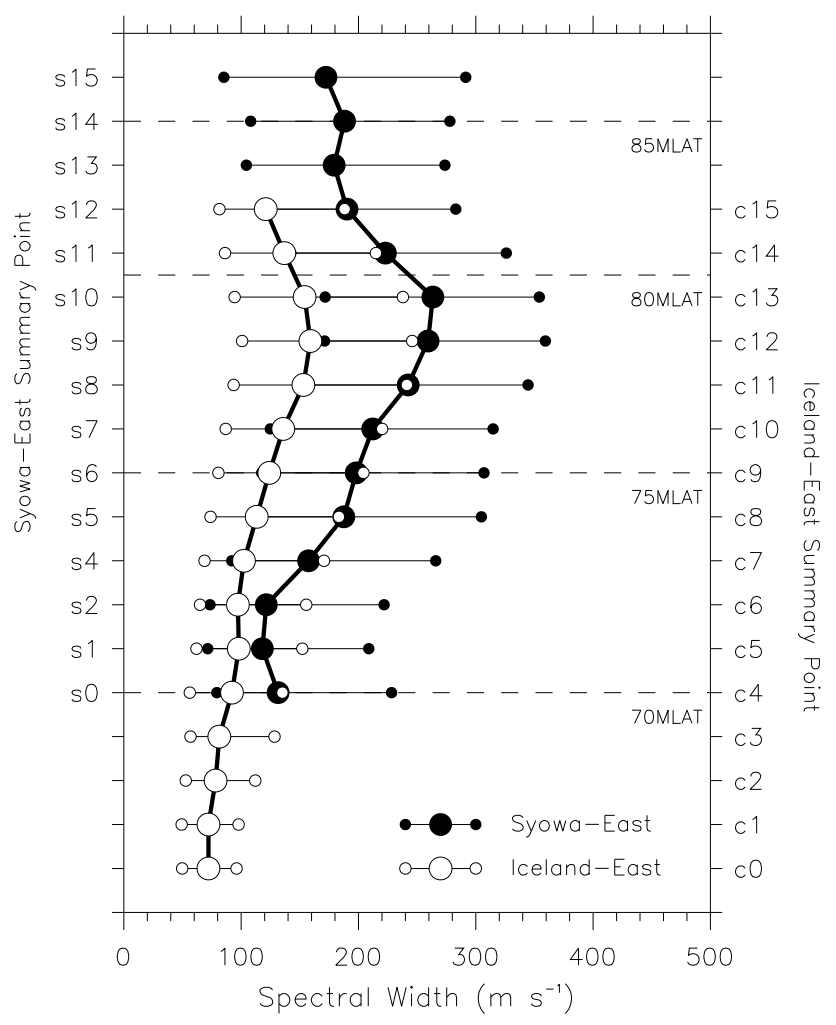

Fig. 8. The median value of the spectral width distribution for Syowa-East and Iceland-East. The results from Syowa-East is displayed as a line with filled circles, those from Iceland-East being displayed as a line with open circles. Filled small circles indicate the upper quartile and lower quartile, respectively.

summer and winter hemispheres, as a consequence of the biases in the reconnection geometries available at the subsolar magnetopause. Pinnock et al. (1999) also presented that there exists a considerable interhemispheric difference in convection velocity around the dayside ionosphere. These observational facts are confirmed by the modeling work of Coleman et al. (2000). This effect is imposed by the tilts of the dipole and rotation axes relative to the Sun-Earth line. As mentioned before, the summary points of Iceland-East and Syowa-East are magnetically conjugate, however, their geographic latitudes and longitudes are different, which might cause an interhemispheric asymmetry in plasma convection patterns observed by the conjugate radars. If the plasma convection has an asymmetry between both hemispheres, then observed spectral widths could also exhibit a considerable difference between conjugate ionospheres by the effect of a gradient in the velocity distribution, as estimated by André et al. (2000a). However, we investigated three whole years of spectral width observations in a statistical fashion. Hence, it is still an open question whether the difference in ionospheric convection could contribute to the interhemispheric asymmetry of spectral width characteristics even in statistical description. Statistical analysis of spectral width using another conjugate radar pair is needed for the further under- 
standing of this interhemispheric difference.

\subsection{Comparison with the other observations}

We now turn to the identification of the cusp and the OCFLB from the HF radar spectral width characteristics. In Fig. 8, the median of the distribution has its maximum at $\mathrm{S} 10$ of Syowa-East and $\mathrm{C} 12$ of Iceland-East, where magnetic latitude $\approx 78.0^{\circ}$. This could be regarded as the statistical location of the cusp center, as determined by the HF radar spectral width characteristics, which is in good agreement between conjugate hemispheres. Newell and Meng (1992) employed the data of the DMSP satellites' dayside passes and clarified the average position of the cusp statistically. They found that the particle precipitations peculiar to the cusp are observed in a region between latitudes of $75.0^{\circ}$ and $82.0^{\circ}$, with the center approximately $78.0^{\circ}$. The statistical location of the cusp center identified by the HF radar and the DMSP is fairly consistent in both hemispheres. Furthermore, the latitude at which the spectral width distribution begins to return to an exponential-like distribution is again similar to the poleward limit of the particle precipitation cusp. These facts confirm that the identification of the cusp, using HF radar spectral width characteristics, is valid for the study of the magnetosphere-ionosphere coupling process in addition to the other observations, such as the particle precipitation and the aurora.

In the study of case examples (e.g. Baker et al., 1997; Pinnock et al., 1999), a well-defined boundary between narrow spectra at a low latitude and broad spectra at a high latitude has been used as a proxy for the OCFLB. This suggests that the transition region between the LLBL-type and the cusp-type spectral width distributions is considered to be the dayside OCFLB in a statistical sense. It is, however, still a considerable debate as to whether the LLBL is on open or closed field lines (for a discussion, see Lockwood, 1997). Hence, we must keep in mind that our statistical estimation of the OCFLB location using spectral width is on the assumption that the LLBL is on a closed field line. The latitudinal location of the OCFLB is highly controlled by the state of the dayside reconnection at the magnetopause, triggered by the north-south component of the IMF. Also, the magnetic latitude of the OCFLB is expected to vary with magnetic local time mainly by the effect of the east-west component of the IMF (Rodger, 2000). Hence, the exact location of the OCFLB cannot be determined by the present statistical analysis, because the data have not been classified by the IMF orientation and magnetic local time sector. However, we can roughly estimate the magnetic latitudes where the OCFLB is normally formed. On the basis of the statistical results from Syowa-East (Fig. 4(a) and Fig. 8), the distribution starts to change remarkably at the magnetic latitude between S5 and S7. These summary points correspond to the magnetic latitudes between $74^{\circ}$ and $76^{\circ}$.

\section{Summary and conclusion}

Characteristics of the spectral width distribution were investigated using the conjugate radar pair composed of CUTLASS Iceland-East in the Northern Hemisphere and SENSU Syowa-East in the Southern Hemisphere.

Three types of spectral width distribution were identified, (1) an exponential-like distribution in the lower magnetic latitudes (below $72^{\circ}$ ), (2) a Gaussian-like distribution around a few degrees magnetic latitude, centered on $78^{\circ}$, and (3) another type of distribution in the higher magnetic latitude (above $80^{\circ}$ ). The first two are considered to represent the LLBL and the cusp, respectively, because they are similar to the spectral width distributions within the LLBL and the cusp as classified by Baker et al. (1995). The distribution found poleward of the cusp has been clarified for the first time in this study. This distribution has similarities to the exponential-like distribution in the lower latitude part of the radar observation, however, clear differences exist in their characteristics.

These features were commonly identified in conjugate hemispheres. The latitudinal transition of the distribution exhibits basically the same trend between two hemispheres, but there is an interhemispheric difference in the form of the distribution within the cusp, such that the spectral width values obtained from Syowa-East are larger than those from Iceland-East. Average locations of the cusp and the open/closed field line boundary (OCFLB) are determined from the spectral width characteristics. The average position of the cusp center is found to be $78^{\circ}$ in AACGM magnetic latitude, which is consistent with the identification of the cusp using the DMSP satellite by Newell and Meng (1992). Also, the OCFLB is identified to be positioned within the magnetic latitude between $74^{\circ}$ and $76^{\circ}$.

Acknowledgements. The Iceland East-Finland radar pair (the Cooperative UK Twin Located Auroral Sounding System : CUTLASS) is funded by the Particle Physics and Astronomy Research Council (PPARC), U.K., under grant PPA/R/R/1997/00256, the Finnish Meteorological Institute, Helsinki, and the Swedish Institute for Space Research, Uppsala. The Ministry of Education, Culture, Sports, Science and Technology supports the Syowa HF radar systems. The 39th, 40th and 41th JAREs have carried out the HF radar operation at Syowa. This research is supported by the Grantin Aid for Scientific Research (A:11304029) from Japan Society for the Promotion of Science (JSPS). This study is funded by a part of 'Ground Research for Space Utilization' promoted by NASDA and Japan Space Forum. EEW is indebted to PPARC for a research studentship.

The Editor in chief thanks two referees for their help in evaluating this paper.

\section{References}

André, R., Pinnock, M., Villain, J.-P., and Hanuise, C.: On the factors conditioning the Doppler spectral width determined from SuperDARN HF radars, Int. J. Geomagn. Aeron., 2, 77, 2000a.

André, R., Pinnock, M., and Rodger, A. S.: Identification of the low-altitude cusp by Super Dual Auroral Radar Network radars: 
A physical explanation for the empirically derived signature, $\mathrm{J}$. Geophys. Res., 105, 27 081, 2000 b.

Baker, K. B. and Wing, S.: A new magnetic coordinate system for conjugate studies of high latitudes, J. Geophys. Res., 94, 9139, 1989.

Baker, K. B., Greenwald, R. A., Ruohoniemi, J. M., Dudeney, J. R., Pinnock, M., Newell, P. T., Greenspan, M. E., and Meng, C.I.: Simultaneous HF radar and DMSP observation of the cusp, Geophys. Res. Lett., 17, 1869, 1990.

Baker, K. B., Dudeney, J. R., Greenwald, R. A., Pinnock, M., Newell, P. T., Rodger, A. S., Mattin, N., and Meng, C.-I.: HFradar signatures of the cusp and low latitude boundary layer, J. Geophys. Res., 100, 7671, 1995.

Baker, K. B., Rodger, A. S., and Lu, G.: HF-radar observations of the rate of magnetic merging: a GEM boundary layer campaign study, J. Geophys. Res., 102, 9603, 1997.

Barthes, L., André, R., Cerisier, J.-C., and Villain, J.-P.: Separation of multiple echoes using a high resolution spectral analysis in SuperDARN HF radars, Radio Sci., 33, 1005, 1998.

Chisham, G. and Pinnock, M.: Assessing the contamination of SuperDARN global convection maps by non-F-region backscatter, Ann. Geophysicae, 20, 13, 2002.

Coleman, I. J., Pinnock, M., Rodger, A. S.: The ionospheric footprint of antiparallel merging regions on the dayside magnetopause, Ann. Geophysicae, 18, 511, 2000.

Greenwald, R. A., Baker, K. B., Dudeney, J. R., Pinnock, M., Jones, T. B., Thomas, E. C., Vilain, J.-P., Cerisier, J.-C., Senior, C., Hanuise, C., Hunsucker, R. D., Sofko, G., Koehler, J., Nielsen, E., Pellinen, R., Walker, A. D. M., Sato, N., and Yamagishi, H.: DARN/SuperDARN: A global view of high-latitude convection, Space Sci. Rev., 71, 763, 1995.

Hosokawa, K., Iyemori, T., Yukimatu, A. S., and Sato, N.: Source of field-aligned irregularities in the subauroral F-region as observed by the SuperDARN radars, J. Geophys. Res., 106, 24713 , 2001.

Huber, M. and Sofko, G.: Small-scale vortices in the high-latitude F-region, J. Geophys. Res., 105, 20885, 2000.

Lockwood, M.: Relationship of dayside auroral precipitations to the open-closed separatrix and the pattern of convective flow, J. Geophys. Res., 102, 17 475, 1997.

Milan, S. E., Yeoman, T. K., Lester, M., Thomas, E. C., Jones, T. B.: Initial Backscatter occurrence statistics from the CUTLASS HF radars, Ann. Geophysicae, 15, 703, 1997.

Milan, S. E., Yeoman, T. K., and Lester, M.: The dayside auroral zone as a hard target for coherent HF radars, Geophys. Res. Lett., 25, 3717, 1998.

Milan, S. E.,Lester, M., Cowley, S. W. H., Moen, J., Sandholt, P. E., and Owen, C. J.: Meridian-scanning photometer, coherent HF radar, and magnetometer observation of the cusp: a case study, Ann. Geophysicae, 17, 159, 1999.

Milan, S. E. and Lester, M.: Interhemispheric differences in the HF radar signature of the cusp region: A review through the study of a case example, Adv. Polar Upper Atmos. Res., 15, 159, 2001.

Milan, S. E., Baddeley, L. J., Lester, M., and Sato, N.: A seasonal variation in the convection response to IMF orientation, Geophys. Res. Lett., 28, 471, 2001a.

Milan, S. E., Lester, M., Cowley, S. W. H., Oksavik, K., Brittnacher, M., Greenwald, R. A., Sofko, G., and Villain, J.-P.: Variation in polar cap area during two substorm cycles, submitted to Ann. Geophysicae, 2001b.

Moen, J., Carlson, C., Milan, S. E., Shumilov, N., Lybekk, B., Sandholt, P. E., and Lester, M.: On the collocation between dayside auroral activity and coherent HF radar backscatter, Ann. Geophysicae, 18, 1531, 2001.

Newell, P. T. and Meng, C. I.: The cusp and the cleft/boundary layer: Low-altitude identification and statistical local time variation, J. Geophys. Res., 93, 14 549, 1988.

Newell, P. T. and Meng, C. I.: Ion acceleration at the equatorward edge of the cusp: low-altitude observations of patchy merging, Geophys. Res. Lett., 18, 1829, 1991.

Newell, P. T. and Meng, C. I.: Mapping the dayside ionosphere to the magnetosphere according to particle precipitation characteristics, Geophys, Res. Lett., 19, 609, 1992.

Rodger, A. S., Mende, S. B., Rosenberg, T. J., and Baker, K. B.: Simultaneous optical and HF radar observations of the ionospheric cusp, Geophys. Res. Lett., 22, 2045, 1995.

Rodger, A. S.: Ground-based imaging of magnetospheric boundaries, Adv. Space Res., 25, 1461, 2000.

Ruohoniemi, J. M. and Greenwald, R. A.: Rates of scattering occurrence in routine HF radar observations during solar cycle maximum, Radio Sci., 32, 1051, 1997.

Pinnock, M., Rodger, A. S., Baker, K. B., Lu, G., and Hairston, M.: Conjugate observations of the day-side reconnection electric field: A GEM boundary layer campaign, Ann. Geophysicae, 17, 443, 1999.

Sandholt, P. E.,Farrugia, C. J., Oieroset, M., Stauning, P., and Denig, W. F.: Auroral activity associated with unsteady magnetospheric erosion: observations on December 19, 1990, J. Geophys. Res., 103, 2309, 1998.

Schiffler, A., Sofko, G., Newell, P. T., and Greenwald, R. A.: Mapping the outer LLBL with SuperDARN double-peaked spectra, Geophys. Res. Lett., 24, 3149, 1997.

Villain, J.-P., Greenwald, R. A., Baker, K. B., and Ruohoniemi, J. M.: HF radar observations of E-region plasma irregularities produced by oblique electron streaming, J. Geophys. Res., 92, $12327,1987$.

Villain, J.-P., André, R., Pinnock, M., Greenwald, R. A., and Hanuise, C.: Statistical study on spectral width from SuperDARN coherent HF radars, Ann. Geophysicae, in press, 2002.

Yeoman, T. K., Lester, M., Cowley, S. W. H., Milan, S. E., Moen, J., and Sandholt, P. E.: Simultaneous observation of the cusp in optical, DMSP and HF radar data, Geophys. Res. Lett., 24, 2251, 1997. 